\title{
Hippocampal afterdischarges and conditioned emotional response
}

\author{
J. DAVID BARCIK \\ Windham College, Putney, Vermont 05346
}

When footshock in a conditioned suppression task is followed by either local or generalized seizure, no suppression develops. The production of a localized seizure produces the same performance decrement as does electroconvulsive shock. These results suggest that the hippocampus is involved in memory processing.

Performance deficit due to electroconvulsive shock (ECS) following a previousiy leamed response has been repeatedly demonstrated (McGaugh, 1966; McGaugh \& Petrinovich, 1966). However, this ECS technique does not provide information as to specific CNS structures involved in the mediation of the performance deficit. Furthermore, Lewis \& Maher $(1965$, 1966) have suggested that, rather than producing amnesia, the ECS produces learning that competes with the retention measure, with the result that performance declines.

Localized seizures in the hippocampus have been produced reliably by several investigators (Delgado \& Sevillano, 1961 ; Elul, 1964a, b; Gutman et al, 1963). Furthermore, hippocampal afterdischarges (HAD) have been produced in a variety of learning situations. Flynn \& Wasman (1960) have concluded that learning occurs during $\mathrm{HAD}$, and thus, seizures in this structure are not involved in the mediation of amnesia. More recently, Hirano (1965) produced $\mathrm{HAD}$ after a learning trial and found no performance deficit. In situations where HAD is associated with a performance decrement, it has been concluded that, unless the afterdischarge spreads to involve the amygdala (Kesner \& Doty, 1968) or cortex (Hirano, 1965), no performance decrement occurs.

Very recent findings, however, suggest that the production of HAD without cortical involvement can result in a passive avoidance deficit (Barcik, 1969). Furthermore, afterdischarge in the hippocampus as a result of intracranial injection of a convulsant has been demonstrated to result in a retention deficit of a CER (Avis, 1969). In order to extend earlier work with passive avoidance as well as with intracranial injection, electrically induced HAD was produced after a footshock and conditioned suppression of a leverpress response was used as a test of retention.

\section{METHOD}

A total of 26 chronically implanted male Wistar rats used previously in passive followed by ECS for seven Ss via cortical screw electrodes (anterior vs contralateral posterior cortex) within $3 \mathrm{sec}$ of footshock offset. A Grass SD-5 stimulator was set to deliver biphasic pulses of $40 / \mathrm{sec}, 1.0-\mathrm{msec}$ pulse width, $30-40 \mathrm{~V}$, for a train duration of approximately $300-900 \mathrm{msec}$. The footshock was followed by HAD for eight $\mathrm{Ss}$ via bilateral bipolar electrodes histologically verified to be in the dorsal hippocampus. Stereotaxic coordinates were $A=3.5 \mathrm{~mm}, L=3.2 \mathrm{~mm}$, and $3.0 \mathrm{~mm}$ below the surface of the cortex (Massopust, 1961). A Grass SD-5 stimulator was set to deliver biphasic pulses of $40 / \mathrm{sec}, 1.0-\mathrm{msec}$ pulse width, $3.0-3.6 \mathrm{~V}$, for a train duration of $10 \mathrm{sec}$. Cross-talk between the footshock and brain stimulation was minimized by isolation of both from ground, as well as with the use of a short shielded cable connecting $S$ with the stimulating and recording circuits. All of the ECS Ss exhibited tonic-clonic seizure and all of the HAD Ss exhibited HAD without overt motor involvement. Three Ss with hippocampal implants did not exhibit $\mathrm{HAD}$ when stimulation was presented. (Thus, it is unlikely that grid shock alone set off the HAD.) These Ss were excluded from the HAD group in the analysis and this constituted the non-HAD (NHAD) group. No brain stimulation was presented to eight implanted control Ss. Thus, there were four groups: control, NHAD, HAD, and ECS.

The CS was presented three times for $1 \mathrm{~min}$ each over the course of the test session on Day 9. During the test session, after a total of 20 responses were made, the number of responses thereafter per 1-min interval was recorded. The first CS
(Campbell \& Teghtsoonian, 1958) footshock was given. The footshock was
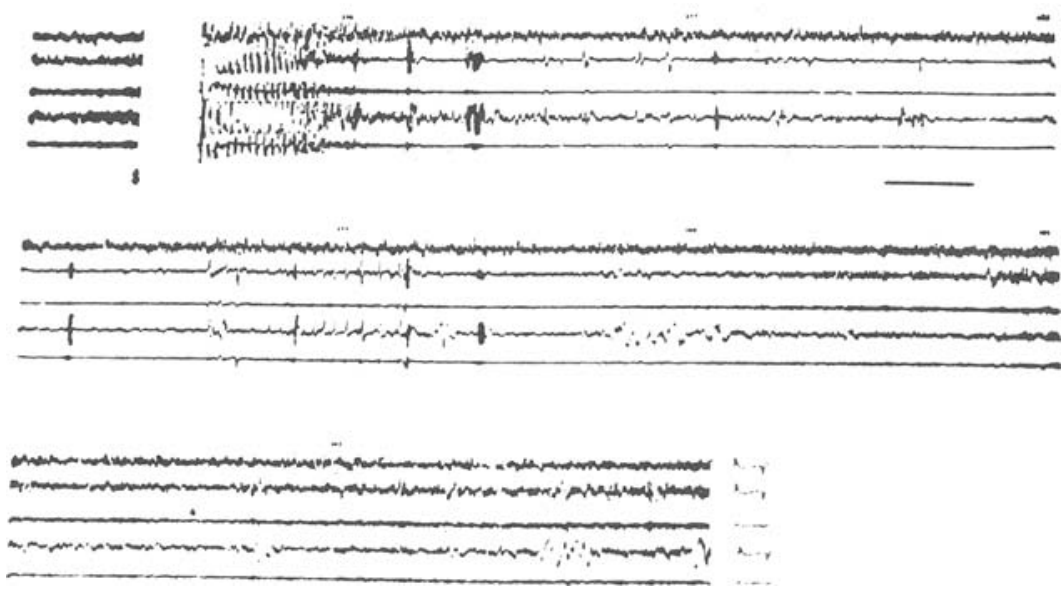

Fig. 1. Cortical and hippocampal recordings before, during, and after a typical HAD: top trace, $L$ vs $R$ frontal cortex; second trace, $L$ hippocampus bipolar; third trace, $L$ vs $R$ hippocampus; fourth trace, $R$ hippocampus bipolar; fifth trace, $L$ vs $R$ hippocampus. The stimulus marker at the break in the record represents a 10-sec train of hippocampal stimulation, 40 pulses per second, $1.0-\mathrm{msec}$ pulse width, and $3.0-\mathrm{V}$ amplitude. Calibrations represent 100 microvolts and 5 sec. 


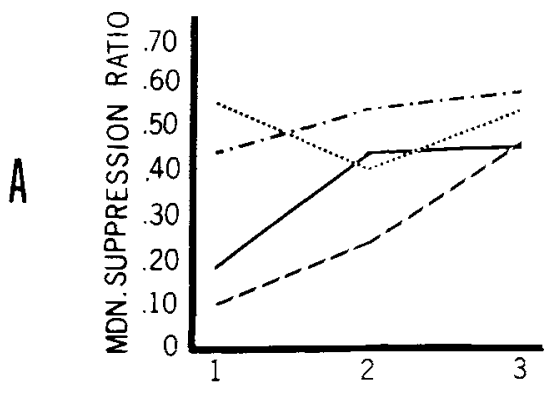

CS PRESENTATION

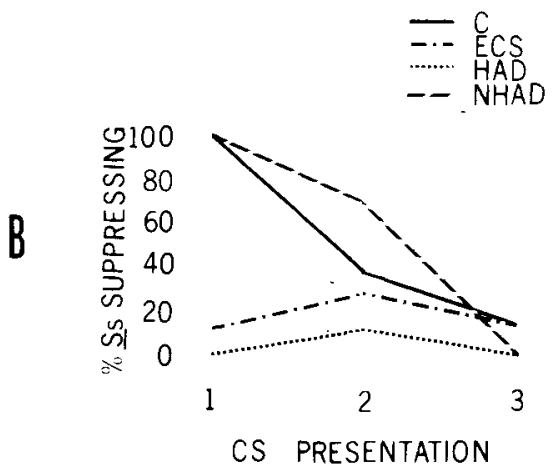

Fig. 2. A. Median suppression ratios for all groups for each CS presentation. B. Percent of subjects suppressing (less than .33 ratio) for all groups for each CS presentation.

presentation never occurred until after approximately $100 \cdot 150$ responses had been made.

\section{RESULTS}

Figure I represents a typical HAD. The seizure patterns for HAD Ss showed remarkably little intra- as well as inter-S variability. Almost all of the seizure patterns started with a high voltage response followed by what appears to be an isoelectric-like pattern that is in turn followed by a second low frequency spiking. The time course of these patterns never exceeded $2 \mathrm{~min}$, after which the records tended toward the prestimulus amplitude. Thus, since the testing did not occur until $24 \mathrm{~h}$ later, proactive effects of the HAD were assumed to be minimal. The Ss did not evidence any noticeable or systematic motor movements during any of the seizure patterns. Also, note that the cortical trace does not indicate cortical involvement during the seizure patterns.

The median suppression ratios (Kamin, 1961) for all groups are summarized in Fig. 2A. The low ratios for the control and NHAD Ss for the first CS presentation shifted toward no suppression with the second and third CS presentations, whereas the HAD and ECS Ss never did show a tendency toward suppression. The differences between the HAD-control and
ECS-control comparisons were statistically significant (Mann-Whitney $U$ values were $p=.001$ and $p=.005$, respectively) for the first CS presentation only. The differences between the HAD-NHAD and ECS-NHAD comparisons were statistically significant (Mann-Whitney $\mathrm{U}$ values were $\mathrm{p}=.006$ and $\mathrm{p}=.05$, respectively) for the first CS presentation only. The ECS and HAD groups were not significantly different for any of the CS presentations, the control and NHAD groups were not significantly different for any of the CS presentations, and there were no statistically significant differences between any of the groups for both the second and third CS presentations.

In order to establish if the CS alone was sufficient to produce suppression, two unimplanted control Ss were run without CS-footshock pairing. On the test day all of the suppression ratios were above .50 for all CS presentations. Thus, it is unlikely that the CS alone was responsible for the suppression shown by control and NHAD Ss.

Figure 2B summarizes the percentage of Ss associated with each of the suppression points. All of the control and NHAD Ss suppressed (suppression was defined as a ratio of less than .33), whereas none of the HAD and $14 \%$ of the ECS Ss suppressed during the first CS presentation. Most of the Ss for all groups except the NHAD group did not suppress during the second CS presentation, whereas almost all Ss did not suppress during the third CS presentation.

\section{DISCUSSION}

The present results clearly indicate that while the production of massive body seizure by ECS results in a performance deficit, this is not a necessary precondition for this deficit. The production of HAD without motor involvement also leads to what appears to be amnesia. Furthermore, if stimulation to the hippocampus is presented and HAD does not develop, retention is clearly demonstrated. This localized seizure (little if any cortical or motor involvement) results in patterns of seizure similar to those produced by intracranial injection of picrotoxin as well as the EEG depression produced by intracranial injection of KCL (Avis, 1969; Avis \& Carlton, 1968). In all cases, the normal activity of the hippocampus is disrupted and in all cases a performance deficit occurs. While normal activity of the hippocampus may be necessary for efficient memory processing, this structure is certainly not the only limbic structure involved in this process (Kesner \& Doty, 1968). Nevertheless, it is clear that the HAD procedure used in this experiment does produce an obvious deficit.
Green (1960) has suggested that the hippocampus has the lowest threshold for seizure discharge. Stimulation of the dorsal hippocampus can lead to violent motor seizures if the afterdischarges spread to other limbic as well as cortical sites. Thus, it is likely that when ECS is presented and amnesia occurs, the hippocampus is involved.

The notion that seizure stimulation produces learning that competes with the retention measure (Lewis \& Maher, 1965 1966) is not supported in this experiment because, instead of coma, the $S$ is capable of integrated action during the HAD (Wasman \& Flynn, 1966). It appears from the present results that the performance deficit produced by HAD after a learning trial reflects amnesia rather than response competition.

\section{REFERENCES}

AVIS, H. H. Retrograde amnesia produced by seizure activity in the hippocampus of the rat Paper read at the Eastern Psychological Association convention, Philadelphia, Pa., 1969.

AVIS, H. H., \& CARLTON, P. L. Retrograde amnesia produced by hippocampal spreading depressiorı. Science, 1969, 161, 73-75.

BARCIK, J. D. Hippocampal afterdischarges and memory disruption. American Psychological Association Proceedings, 1969, 185-186.

CAMPBELL, B. A., \& TEGHTSOONIAN, R. Electrical and behavioral effects of different types of shock stimuli on the rat. Journal of Comparative \& Physiological Psychology, 1958, 51, 185-192.

DELGADO, J. M. R., \& SEVILLANO, M. Evolution of repeated hippocampal seizures in the cat. EEG \& Clinical Neurophysiology, 1961, 13, 722-733.

ELUL, R. Regional differences in the hippocampus of the cat. I. Specific discharge patterns of the dorsal and ventral hippocampus and their role in generalized seizures. EEG \& Clinical Neurophysiology, 1964a, 16, 470-488.

ELUL, $R$. Regional differences in the hippocamous of the cat. II. Projections of the dorsal arid ventral hippocampus. EEG \& Clinical Neurophysiology. 1964b, 16, 489-502.

FLYNN, J. P. \& WASMAN, M. Learning and cortically evoked movement during propagated hippocampal afterdischarges. Science, 1960 , $131,1607-1608$

GREEN, J. D. The hippocampus. In J. Field, H. W. Magoun, and V. E. Hall (Eds.), Handbook of physiology. Vol. II. Baltimore: Williams \& Wilkins, 1960. Pp. 1373-1389.

GUTMAN, J., COSTIN, A., \& BERGMANN, I. Constancy of hippocampal afterdischarges under various conditions of stimulation. EEG \& Clinical Neurophysiology, 1963, 15, 989-996.

HIRANO, T. Effects of functional disturbances of the limbic system on the memory consolidation. Japanese Psychological Research, 1965, 7, 171-182.

KAMIN, L. J. Trace conditioning of the conditioned emotional response. Joumal of Comparative \& Physiological Psychology, 1961, 54, 149-153.

KESNER, R.. \& DOTY, R. W. Amnesia produced in -uts by local scizure activity initiated from the amygrala. Experimental Neurology. 1968. $21,58-68$

LIEWIS, D. J.. \& MAHER, B. A. veural 
consolidation and electroconvulsive shock. Psychological Review, 1965, 72, 225-239.

LEWIS, D. J., \& MAHER, B. A. Electroconvulsive shock and inhibition: Some problems considered. Psychological Review, $1966,73,388-392$.

McGAUGH, J. L. Time dependent processes in memory storage. Science, 1966, 153 , 1351-1358.

McGAUGH, J. L., \& PETRINOVICH, L. F.
Neural consolidation and electroconvulsive shock re-examined. Psychological Review, 1966, 73, 382-387.

MASSOPUST, L. C., JR. Diencephalon of the rat. In D. E. Sheer (Ed.), Electrical stimulation of the brain. Austin: University of Texas Press, 1961. Pp. 182-202.

WASMAN, M., \& FLYNN, J. P. Directed attack behavior during hippocampal seizures. Archives of Neurology, 1966, 14, 408-414.

\section{Rat activity as a function of water deprivation and age}

\author{
JAMES R. FRAZIER* \\ Florida State University, Tallahassee, Fla. 32306
}

Four rats were water deprived for $24,48,72,96$, and $120 \mathrm{~h}$, beginning at ages 37,59 , and 81 days. Naive ( 37 days) Ss increased activity over baseline after $24 \mathrm{~h}$; deprivation-experienced $S s$ showed activity decrements after $24 \mathrm{~h}$. All Ss sharply decreased activity at $120 \mathrm{~h}$ at each age interval.

Several studies have reported rat activity in photoelectric cages as a function of water deprivation at a single age level (Finger, 1962; Grimsley, 1965). Using a $3 \frac{1}{2}-$-in-wide circular alley bisected by light beams, Grimsley (1965) found a trend toward daily activity increments under 0 , $24,48,72$, and $96 \mathrm{~h}$ of water deprivation for 90 - to 110-day-old rats. Finger (1962) measured daily activity of 40-day-old rats under 24 and $48 \mathrm{~h}$ of deprivation. Compared to baseline activity, he found median performance decrements to be $29.5 \%$ and $43.0 \%$, respectively, for 24 and $48 \mathrm{~h}$ of deprivation. The present study replicated certain aspects of Finger's study, but extended deprivation and age parameters.

\section{METHOD}

The Ss were four male rats from the Dublin laboratories maintained on an illumination cycle of $12 \mathrm{~h}$ light and $12 \mathrm{~h}$ dark, the former beginning at 7:30 a.m. The home cage served as the experimental apparatus. This wire-mesh cage was a replica of Finger's (1962) apparatus. The dimensions were 22 in. long $x 8$ in. high $x$ 8 in. wide, with both length and width bisected by a photocell beam. Interruption of the beam activated an external counter that recorded the responses. A food cup containing Purina Lab Chow was attached

*Author now at the Child Development Institute, University of North Carolina. Chapel Hill, N.C. 27514. to a side near the front, through which projected the water tube. Cages were housed under normal laboratory conditions, with the average temperature $75^{\circ} \mathrm{F}$ and relative humidity $45 \%$.

The Ss were weaned at approximately 20 days of age, and baseline measures began the 28 th day. Food and water were ad lib for a 9-day adaptation period until activity stabilized. Stability was determined by visual inspection of the data. During the last hour of each day's light cycle, Ss were weighed to the nearest

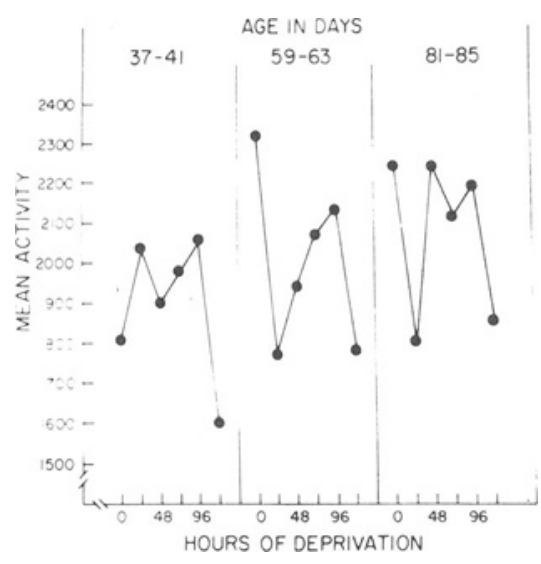

Fig. 1. Mean activity as a function of hours of water deprivation at three age levels. Each point represents total number of beam interruptions during a $23-\mathrm{h}$ period for four animals. gram, food and water intake was recorded to the nearest gram and milliliter for the previous $23 \mathrm{~h}$, and general maintenance was accomplished. Total daily activity was recorded from the counters as number of beam interruptions for that period.

When the Ss were 37 days of age, water bottles were removed from all Ss after the maintenance period and deprivation was continued for $120 \mathrm{~h}$ ( 5 days). No other change in conditions occurred and water was returned after the 5-day interval. Daily measures were taken of weight, food and water consumption, and activity, just as in adaptation. This procedure was recycled every 22 days, allowing 17 days between deprivation periods for $S s$ to recover weight losses and stabilize food and water intake. Thus each animal was deprived beginning at 37,59 , and 81 days of age.

\section{RESULTS}

Total number of beam interruptions during $23 \mathrm{~h}$ constituted the activity measure. Figure 1 represents mean number of beam interruptions associated with deprivation hours and age. From baseline, naive ( 37 days) Ss' activity increased across 4 days and dropped sharply on Day 5. After deprivation experience 59. and 81-day-old Ss decreased responding the first day, generally increased responding through Day 4 , and reduced activity on Day 5 .

\section{DISCUSSION}

Present data do not support previous findings of activity decrements for 40-day-old rats 24 and $48 \mathrm{~h}$ water deprived (Finger, 1962). However, Finger's Ss were $48 \mathrm{~h}$ food deprived, received a 10-day recovery period, then $48 \mathrm{~h}$ deprived. Perhaps these procedural differences are related to disparity in results.

If one compares data using $S s$ with deprivation experience, irrespective of kind of deprivation, similar trends between Finger's results and present data emerge. Finger's water-deprived Ss, following food deprivation and recovery, decreased total daily activity from baseline by $30 \%$ and $40 \%$, respectively, after 24 and $48 \mathrm{~h}$ of deprivation. Water deprivation experienced animals in this study, 59 days old, decreased total daily activity by $26 \%$ and $17 \%$, respectively, after 24 and $48 \mathrm{~h}$. Thus the trends suggest that experience with prior deprivation, at least in young animals, might be a factor to consider in any interpretation of water deprivation effects on measures of activity.

\section{REFERENCES}

FINGER, F. W. Activity under deprivation as a function of age. Joumal of Comparative \& Physiological Psychology, 1962, 55, 100-102. GRIMSLEY, D. L. Effects of water deprivation and injections of hypertonic saline on the activity of rats. Psychological Reports, 1965 , $16,1081-1085$. 